\title{
Torquenema n. g., Wallabicola n. g., and Macropostrongyloides phascolomys n. sp.: New Genera and a New Species of Nematode (Strongylida: Phascolostrongylinae) Parasitic in Australian Macropodid and Vombatid Marsupials
}

\author{
Tanapan Sukee *(D), Ian Beveridge * and Abdul Jabbar (D) \\ Department of Veterinary Biosciences, Melbourne Veterinary School, Faculty of Veterinary and Agricultural \\ Sciences, The University of Melbourne, Melbourne, VIC 3030, Australia; jabbara@unimelb.edu.au \\ * Correspondence: tsukee@student.unimelb.edu.au (T.S.); ibeve@unimelb.edu.au (I.B.)
}

check for

updates

Citation: Sukee, T.; Beveridge, I.; Jabbar, A. Torquenema n. g., Wallabicola n. g., and Macropostrongyloides phascolomys n. sp.: New Genera and a New Species of Nematode (Strongylida: Phascolostrongylinae) Parasitic in Australian Macropodid and Vombatid Marsupials. Animals 2021, 11, 175. https://doi.org/ 10.3390/ani11010175

Received: 9 December 2020 Accepted: 6 January 2021 Published: 13 January 2021

Publisher's Note: MDPI stays neutral with regard to jurisdictional clai$\mathrm{ms}$ in published maps and institutional affiliations.

Copyright: (C) 2021 by the authors. Licensee MDPI, Basel, Switzerland. This article is an open access article distributed under the terms and conditions of the Creative Commons Attribution (CC BY) license (https:// creativecommons.org/licenses/by/ $4.0 /)$.
Simple Summary: This article describes two new genera of parasitic nematodes, Torquenema n. $\mathrm{g}$. from the eastern grey kangaroo and Wallabicola n. g. from the swamp wallaby, and a new species, Macropostrongyloides phascolomys n. sp. from the caecum of the common wombat.

\begin{abstract}
The strongyloid nematodes belonging to the subfamily Phascolostrongylinae occur primarily in the large intestines of macropodid and vombatid marsupials. Current molecular evidence suggests that the two nematode species, Macropostrongyloides dissimilis and Paramacropostrongylus toraliformis, from macropodid marsupials are distant from their respective congeners. Furthermore, specimens of Macropostrongyloides lasiorhini from the large intestines of the southern hairy-nosed wombat (Lasiorhinus latifrons) and the common wombat (Vombatus ursinus) are genetically distinct. This study aimed to describe the new genera Torquenema $\mathrm{n}$. g. (with T. toraliforme $\mathrm{n}$. comb. as the type species) from the eastern grey kangaroo, Wallabicola $n$. g. (with $W$. dissimilis $n$. comb. as the type species) from the swamp wallaby and a new species Macropostrongyloides phascolomys $\mathrm{n}$. sp. from the common wombat, using light and scanning electron microscopy.
\end{abstract}

Keywords: parasites; Phascolostrongylinae; kangaroos; wallabies; wombats; marsupials; taxonomy

\section{Introduction}

The strongyloid nematode subfamily, Phascolostrongylinae Lichtenfels, 1980 is currently represented by seven genera and 19 species found in kangaroos, wallabies, and wombats (Macropodidae and Vombatidae) [1]. The Phascolostrongylinae has been subdivided into three tribes based on morphological features [1]. One of the tribes is the Macropostrongyloidinea, which comprises the genera Macropostrongyloides Yamaguti, 1961 and Paramacropostrongylus Johnston and Mawson, 1940, and they are generally characterised by small cylindrical buccal capsules with a distinctive Y-shaped dorsal gutter and the presence of peri-oral teeth or denticles [1]. Although the majority of species within the Phascolostrongylinae are restricted to the large intestines of their hosts, several exceptional species, all belonging to the tribe Macropostrongyloidinea, have been found within the stomachs of macropodid marsupials [2].

A recent molecular study based on the first and second internal transcribed spacers (ITS-1 and ITS-2) of the nuclear ribosomal DNA revealed that the genera Macropostrongyloides and Paramacropostrongylus were paraphyletic, with Macropostrongyloides dissimilis Johnston and Mawson, 1939 and Paramacropostrongylus toraliformis Beveridge and Mawson, 1978 distinct from their respective congeners [3]. The study found that $M$. dissimilis, a dark-red nematode from the stomach of the swamp wallaby Wallabia bicolor (Desmarest) is a sister taxon to the only other stomach-inhabiting phascolostrongyline species Paramacrop- 
ostrongylus typicus Johnston and Mawson, 1940 and Paramacropostrongylus iugalis Chilton, Beveridge and Andrews, 1993 from grey kangaroos [3].

Macropostrongyloides dissimilis was originally assigned to the genus Cyclostrongylus Johnston and Mawson 1939, but a subsequent revision found that the species shared greater similarities with its current genus, Macropostrongyloides [4]. Paramacropostrongylus toraliformis was described from the caecum of the eastern grey kangaroo, Macropus giganteus Shaw. This species differed at that time from the only congener, Paramacropostrongylus typicus in the presence of a prominent cephalic collar which extends beyond its body [2].

Macropostrongyloides lasiorhini Mawson, 1955 is the only species of Macropostrongyloides parasitic in the large intestine of wombats. Molecular data also detected genetic differences between nematodes from the southern hairy-nosed wombat, Lasiorhinus latifrons (Owen) and the common wombat, Vombatus ursinus (Shaw) [5].

\section{Materials and Methods}

\subsection{Collection of Specimens}

Specimens were borrowed from the Australian Helminthological Collection, South Australian Museum (SAM), Adelaide and the Australian National Wildlife Collection (ANWC), Commonwealth Scientific and Industrial Research Organisation (CSIRO), Canberra, or collected from road killed hosts and stored in ethanol at $-80^{\circ} \mathrm{C}$ until required. These latter specimens have now been deposited in SAM.

\subsection{Light Microscopy}

Specimens were mounted on glass slides in lactophenol and examined under a compound microscope (Olympus BH-2, Olympus Optical CO., LTD., Tokyo, Japan). Illustrations were made using a drawing tube attached to a $\mathrm{BH}-2$ Olympus microscope and digitised in Adobe Photoshop CC 2019. Measurements are presented in millimetres as ranges followed by the mean in parenthesis. The lengths and widths of the buccal capsule were taken from the external surface.

Morphological terminology follows that of Beveridge and Mawson [2] except for the papillae of the genital cone which follows the numerical system of Chabaud et al. [6]. Host nomenclature follows Jackson and Groves [7]. In instances where collection localities were within approximately $50 \mathrm{~km}$ of one another, records of occurrences were combined.

\subsection{Scanning Electron Microscopy}

Specimens for scanning electron microscopic (SEM) examination were dehydrated in an ethanol series with concentrations beginning at 70\%, followed by 1:1 ratio of ethanol and hexamethyldisilazane (HMDS) (ProSciTech Pty. Ltd., Queensland, Australia) and finally with pure HMDS. The dehydrated specimens were air-dried and mounted onto stubs with double-sided carbon conductive tape, coated in gold and observed in a FEI XL30 FEG scanning electron microscope (Thermo Fisher Scientific Inc., Massachusetts, MA, USA).

\section{Results}

3.1. Description of a New Genus, Torquenema n. $g$.

Order Strongylida (Molin, 1861)

Family Chabertiidae (Popova, 1952)

Subfamily Phascolostrongylinae Lichtenfels, 1980

Torquenema n. g.

Type species: Torquenema toraliforme (Beveridge and Mawson, 1978) n. comb.

\subsubsection{Generic Definition}

Robust nematodes. Cephalic collar large, disc-shaped, extending peripherally beyond body; collar pierced by four sub-conical, sub-median papillae and two lateral amphids; mouth opening circular; buccal capsule sub-cylindrical, heavily sclerotised; anterior extremity bears c. 25 triangular projections forming leaf crown; teeth absent in buccal capsule; 
duct of dorsal oesophageal gland pierces wall of buccal capsule at mid-length, divides internally to form Y-shaped dorsal gutter. Oesophagus clavate; nerve ring in anterior third of oesophagus; deirid papillate, posterior to nerve ring; excretory pore at same level as deirid. Spicules elongate, alate. Vulva immediately anterior to anus; ovejector Y-shaped; eggs ellipsoidal. Parasitic in macropodid marsupials.

\subsubsection{Redescription of Torquenema toraliforme $\mathrm{n}$. comb.}

Torquenema toraliforme (Beveridge and Mawson, 1978) n. comb.

Synonyms: Paramacropostrongylus toraliformis Beveridge and Mawson, 1978.

Types: holotype, SAM 41299; allotype, SAM 41300.

Type host: Macropus giganteus Shaw (Marsupialia: Macropodidae).

Type locality: Yan Yean, Victoria, Australia ( $\left.37^{\circ} 34^{\prime} \mathrm{S} 145^{\circ} 06^{\prime} \mathrm{E}\right)$.

Additional material examined: Queensland: $10^{7}, 30 \mathrm{~km}$ E of Inglewood (SAM 33088), $10^{7}$, Warwick (SAM 49053); New South Wales: $20^{\circ} 0^{\circ}$, Girilambone (SAM 33572); $100^{\circ} 0^{\circ}, 12 \circ \%$, Kingstown (SAM 6730); 3우, Armidale (SAM 6765); $40^{7} 0^{7}, 3 \circ \circ, 45 \mathrm{~km}$ NE of Coonabarabran (SAM 44383); $40^{7} 0^{7}, 3$, 3ㅇ, Kioloa (SAM 48486); Victoria: $320^{7} \sigma^{7}, 62 \% 9$, Dartmouth (SAM 9209, 9244); 1우, Mitta Mitta (SAM 12060); $80^{\top} 0^{\circ}$, 1우, Fraser National Park (SAM 11049); 1우,

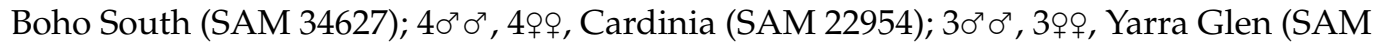

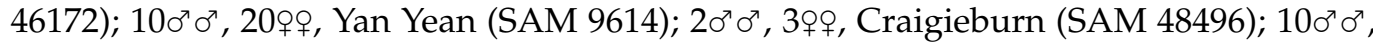
12우, Lara (SAM 33122); $20^{7} 0^{7}, 5$ 우, Anglesea (SAM 44435).

Site in host: Caecum.

Representative DNA sequences: Ribosomal DNA first and second internal transcribed spacers sequences (Genbank Accession MT396206) from M. giganteus, Research, Victoria, Australia [3].

Etymology: The new generic name is derived from 'torquem' which means collar in Latin and refers to the prominent cervical collar of Torquenema $\mathrm{n}$. $\mathrm{g}$. The specific name has been changed to toraliforme $\mathrm{n}$. comb. in agreement with the neuter generic name.

\subsubsection{Redescription}

General (Figure 1a-d, Figures 2a-g and 3a,b). Robust nematodes, red or pink in colour when fresh. Body covered with numerous transverse annulations, c. 0.005 apart, with gaps between annulations along lateral surfaces of body. Cephalic collar enlarged, discshaped, extending peripherally beyond body; anterior surface divided by fine sutures visible with SEM, one surrounding cephalic papillae and amphids, outer suture close to peripheral margin (Figure 3a,b); outer region of collar with internal cavity, semi-lunar in shape in transverse section; inner region of collar pierced by four sub-conical, sub-medial papillae and two lateral amphids; mouth opening circular; buccal capsule sub-cylindrical, heavily sclerotised, longer than wide, with numerous inconspicuous internal longitudinal ridges, most readily visible in lateral views towards base of buccal capsule; anterior extremity bears c. 25 triangular projections forming leaf crown; teeth absent in buccal capsule; wall of buccal capsule complex with internal structure sub-divided; duct of dorsal oesophageal gland pierces wall of buccal capsule at mid-length, divides internally to form Y-shaped dorsal gutter, with branches passing internally near anterior margin of buccal capsule, joining ventrally. Oesophagus clavate; ventral sectors of oesophagus project prominently into base of buccal capsule; dorsal sector projects slightly into base of buccal capsule; nerve ring in anterior third of oesophagus; deirid papillate, posterior to nerve ring; excretory pore at about same level as deirid. 


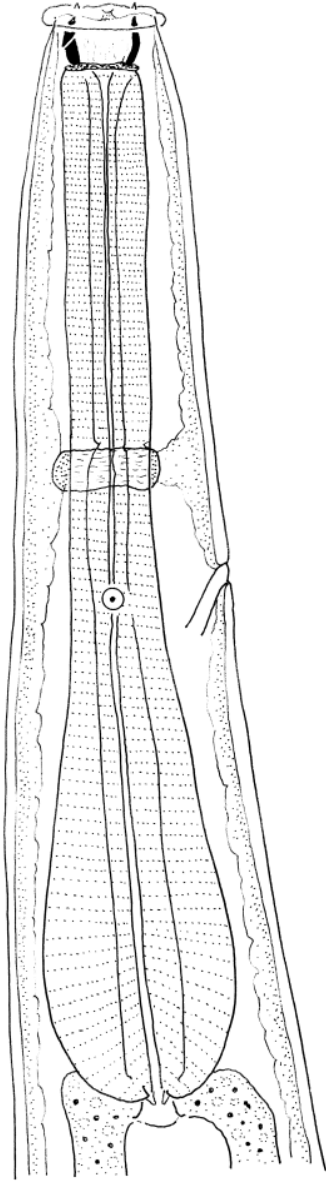

$\mathbf{a}$

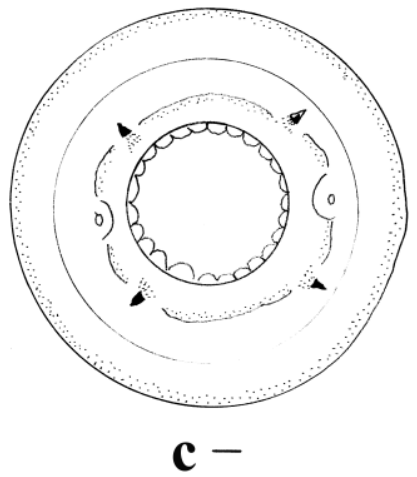

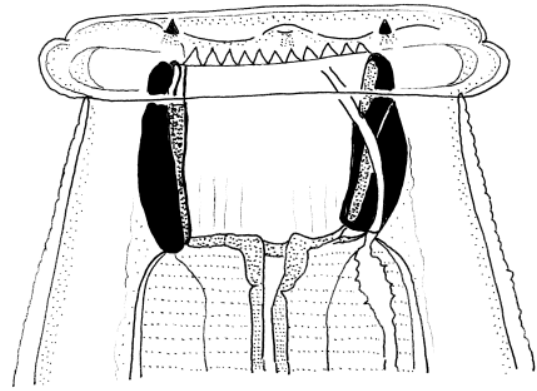
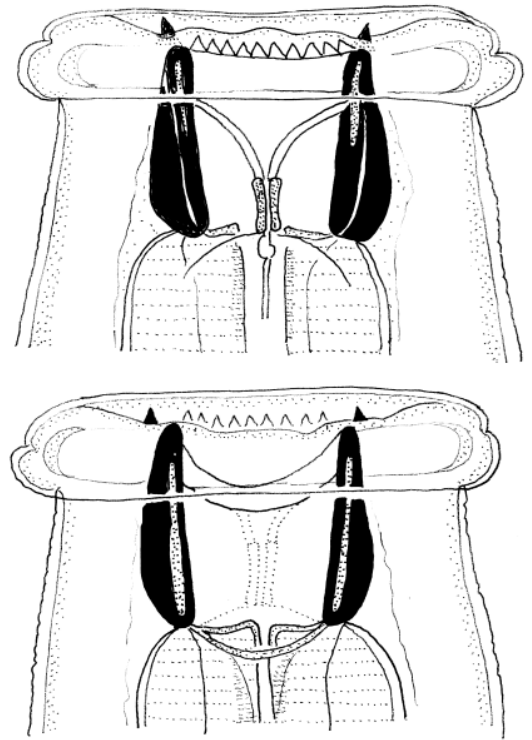

b

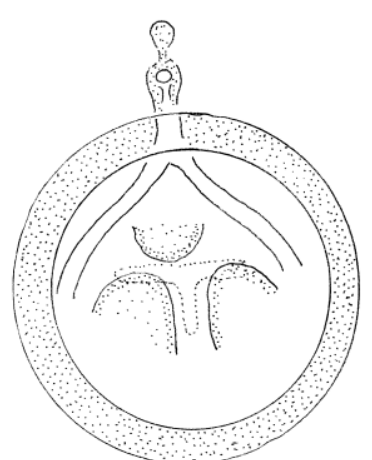

d -

Figure 1. Torquenema toraliforme n. comb. (a) Anterior region, right lateral view; (b) Buccal capsule, dorsal and lateral views; (c) Anterior extremity, apical view; (d) Buccal capsule, optical transverse section. Scale-bars: (a), $0.1 \mathrm{~mm}$; (b-d), $0.01 \mathrm{~mm}$. 

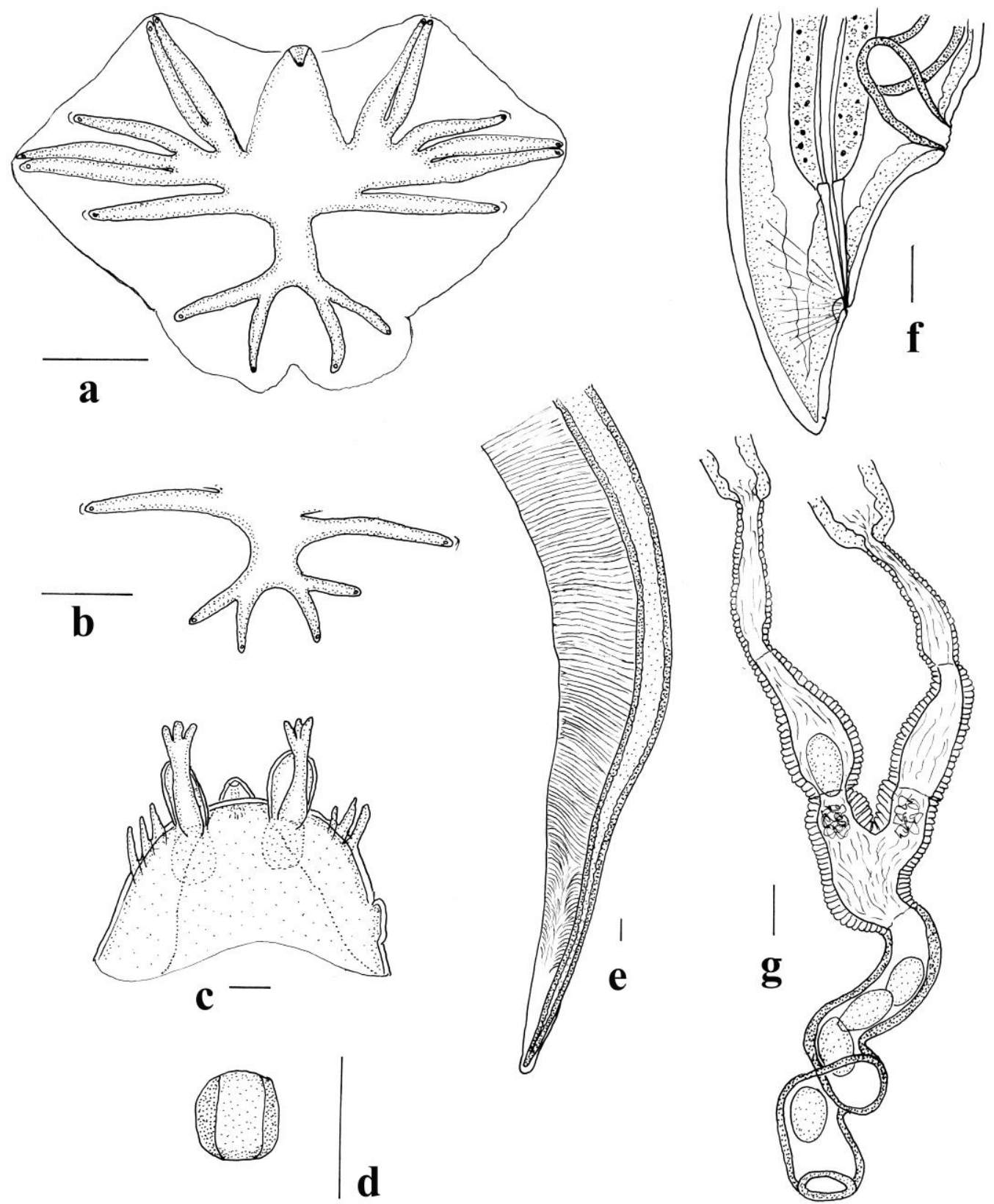

Figure 2. Torquenema toraliforme n. comb. (a) Bursa, apical view; (b) Dorsal ray of bursa, dorsal view; (c) Genital cone, dorsal view; (d) Gubernaculum; (e) Spicule tip, lateral view; (f) Female tail, lateral view; (g) Vagina and ovejector, lateral view. Scale-bars: (a,b,f-g), $0.1 \mathrm{~mm} ;(\mathbf{c}-\mathbf{e}), 0.01 \mathrm{~mm}$. 


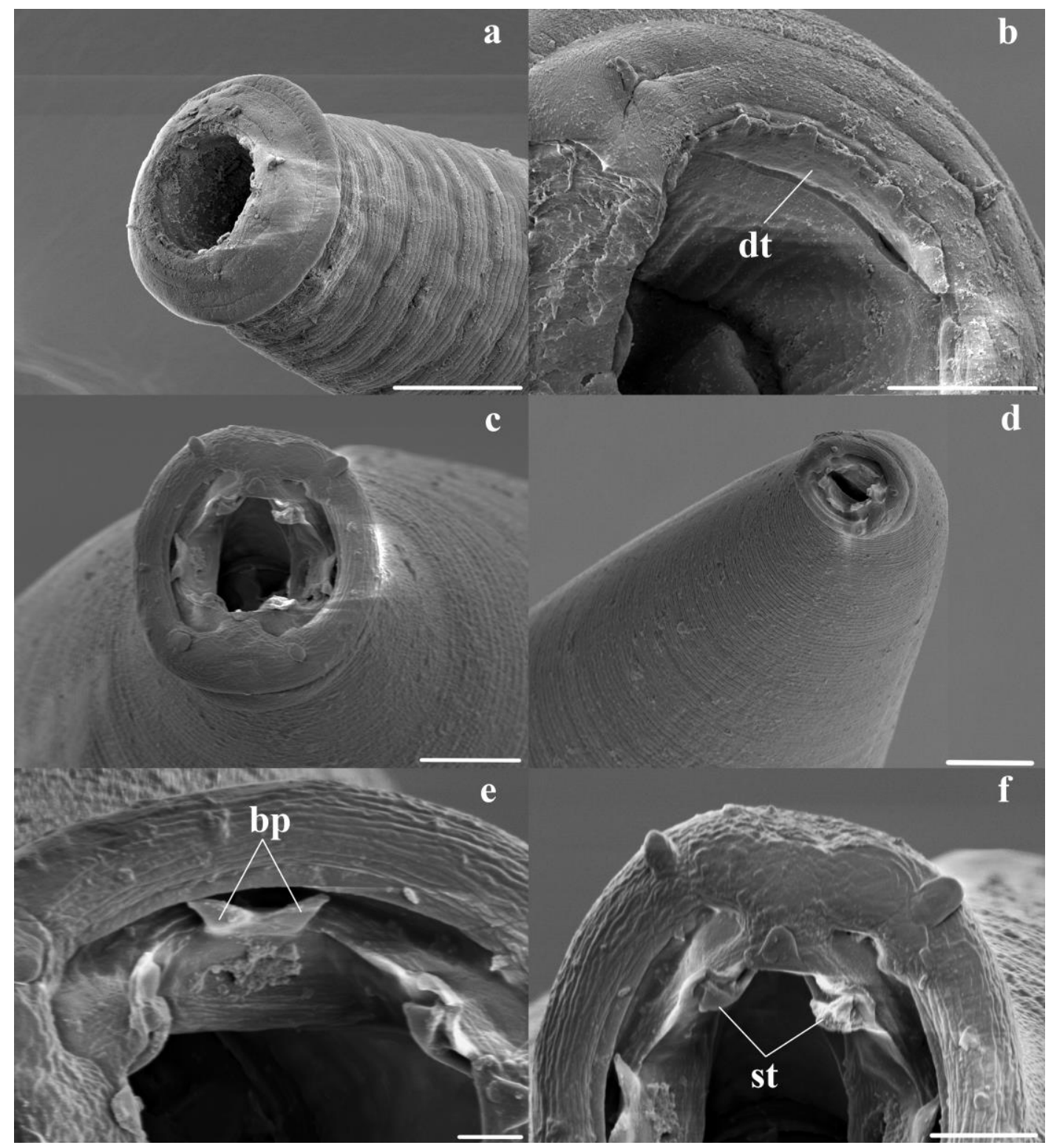

Figure 3. Scanning electron photomicrographs of the cephalic extremities and mouth openings. (a) Anterior extremity of Torquenema toraliforme $\mathrm{n}$. comb. showing collar; (b) Buccal capsule, apical view of Torquenema toraliforme $\mathrm{n}$. comb.(dt = denticles); (c) Buccal capsule, apical view of Wallabicola dissimilis n. comb.; (d) Anterior extremity of Wallabicola dissimilis $\mathrm{n}$. comb., showing ventral deviation of head; (e,f) Buccal capsule, apical view of Wallabicola dissimilis n. comb. showing bifid projection (bp) (e) and sub-median teeth (st) (f). Scale-bars: (a), $50 \mu \mathrm{m} ;(\mathbf{b}, \mathbf{d}), 20 \mu \mathrm{m} ;(\mathbf{c}), 10 \mu \mathrm{m}$; (e), $2 \mu \mathrm{m} ;(\mathbf{f}), 5 \mu \mathrm{m}$.

Male (measurements of 10 specimens). Length 13-20 (16); maximum width $0.43-0.61$ (0.53); buccal capsule 0.070-0.080 (0.078) deep, 0.060-0.070 (0.061) wide; width of cephalic collar 0.13-0.15 (0.14); oesophagus 0.88-1.26 (1.17) long; nerve ring, excretory pore and deirid 0.46-0.56 (0.52), 0.59-0.75 (0.67) and 0.63-0.78 (0.72) from anterior end respectively. Bursa short, stout; lateral and ventral lobes fused, ventral lobes joined ventrally; dorsal lobe shorter than ventro-lateral lobes, with slight median indentation. Ventro-ventral and ventro-lateral rays apposed, reaching margin of bursa; externo-lateral ray divergent from lateral trunk, not reaching margin of bursa, terminating in slight elevation on surface of bursa; medio-lateral and postero-lateral rays apposed, reaching margin of bursa; externolateral ray between lateral and dorsal trunks, not reaching margin of bursa, terminating in slight elevation on surface of bursa; dorsal ray slender at origin, dividing at mid- 
length; external branchlets directed postero-laterally, not reaching margin of bursa; internal branchlets arcuate, directed posteriorly, not reaching margin of bursa; spicules 2.95-3.45 (3.25) long, alate; alae with numerous transverse striations; anterior extremity of spicules irregularly knobbed; distal extremity curved, terminating in blunt tip; ala diminishes gradually towards distal tip of spicule, losing transverse striations; ventral lip of genital cone conical, bearing papilla 0; dorsal lip with paired appendages (papillae 7) closely applied to cloaca; dorsal to each of them, distally trifid projection; 3-4 elongate, simple projections lateral to each side of central projections; gubernaculum prominent, ovoid and laterally elongated in dorso-ventral view $0.13-0.15$ (0.14) long.

Female (measurements of 10 specimens). Length 23-32 (27); maximum width 0.73-0.88 (0.79); buccal capsule 0.080-0.100 (0.090) deep, 0.006-0.007 (0.064) wide; width of cephalic collar 0.15-0.18 (0.16); oesophagus 1.28-1.60 (1.43) long; nerve ring, excretory pore and deirid $0.51-0.63(0.58), 0.64-0.96(0.78)$ and $0.64-0.99$ (0.74) from anterior end respectively. Tail short conical, $0.24-0.30(0.26)$; vulva $0.52-0.73$ (0.60) from posterior end; vagina convoluted 0.50-0.61 (0.58) long; ovejector Y-shaped, c. 0.35 long; vestibule elongate, c. 0.36 long; infundibulum elongate with decreased muscular investment, c. 0.30 long; eggs thin-shelled, ellipsoidal 0.12-0.15 (0.14) long, 0.06-0.08 (0.07) wide.

\subsubsection{Remarks}

Torquenema $\mathrm{n}$. g. is distinguishable from all other phascolostrongyline genera by the presence of a large disc-shaped cephalic collar which protrudes beyond its body margin. Torquenema n. g. differs from Paramacropostrongylus by the Y-shaped ovejector and its occurrence within the caecum of the host.

The current re-description of T. toraliforme n. comb. largely supports that of Beveridge and Mawson [2] and Beveridge [1], while providing additional details, particularly those shown by SEM. Beveridge and Mawson [2] reported the mouth opening of P. toraliformis as being surrounded by about 20 'denticles'. Their apical view of the mouth opening (Figure 59 in Beveridge and Mawson [2]) shows 23 'denticles' which is closer to the 25 estimated in the current description. However, the current SEM observations of Torquenema $\mathrm{n}$. $\mathrm{g}$. (Figure 3a,b) suggest that these 'denticles' are not separate entities but form a continuous structure around the anterior margin of the buccal capsule, resembling a leaf crown. Consequently, they have here been described as such. The extent to which this situation differs from Paramacropostrongylus will require additional SEM studies of this genus.

One of the principal morphological features used to separate the Phascolostrongylinae from the Cloacininae has been the origin of the externo-dorsal ray, arising from the dorsal trunk in the Phascolostrongylinae and from the lateral trunk in the Cloacininae. However, in Torquenema n. g., the externo-dorsal ray arises between the lateral and dorsal trunks, a feature partially recognised by Beveridge and Mawson [2] in their definition of Paramacropostrongylus in which they state 'externo-dorsal ray arising from dorsal ray or separately'. Although uncommon within the Cloacininae, Beveridge [8] described two species of Cloacina in which the externo-dorsal ray arises from the dorsal ray. The current description of the genital cone differs slightly from that illustrated by Beveridge and Mawson [2] in that their Figure 62 lacks the actual papillae 7 on the dorsal lip, which are overshadowed by the paired appendages dorsal to them.

The geographic distribution of T. toraliforme $\mathrm{n}$. comb. corresponds to some degree with the distribution of its host, $M$. giganteus (Figure 4). Collection records show that T. toraliforme n. comb. is most commonly encountered in Victoria and some parts of New South Wales. However, T. toraliforme n. comb. appears to be absent from Queensland except for areas around Inglewood, close to the New South Wales border (Figure 4). 


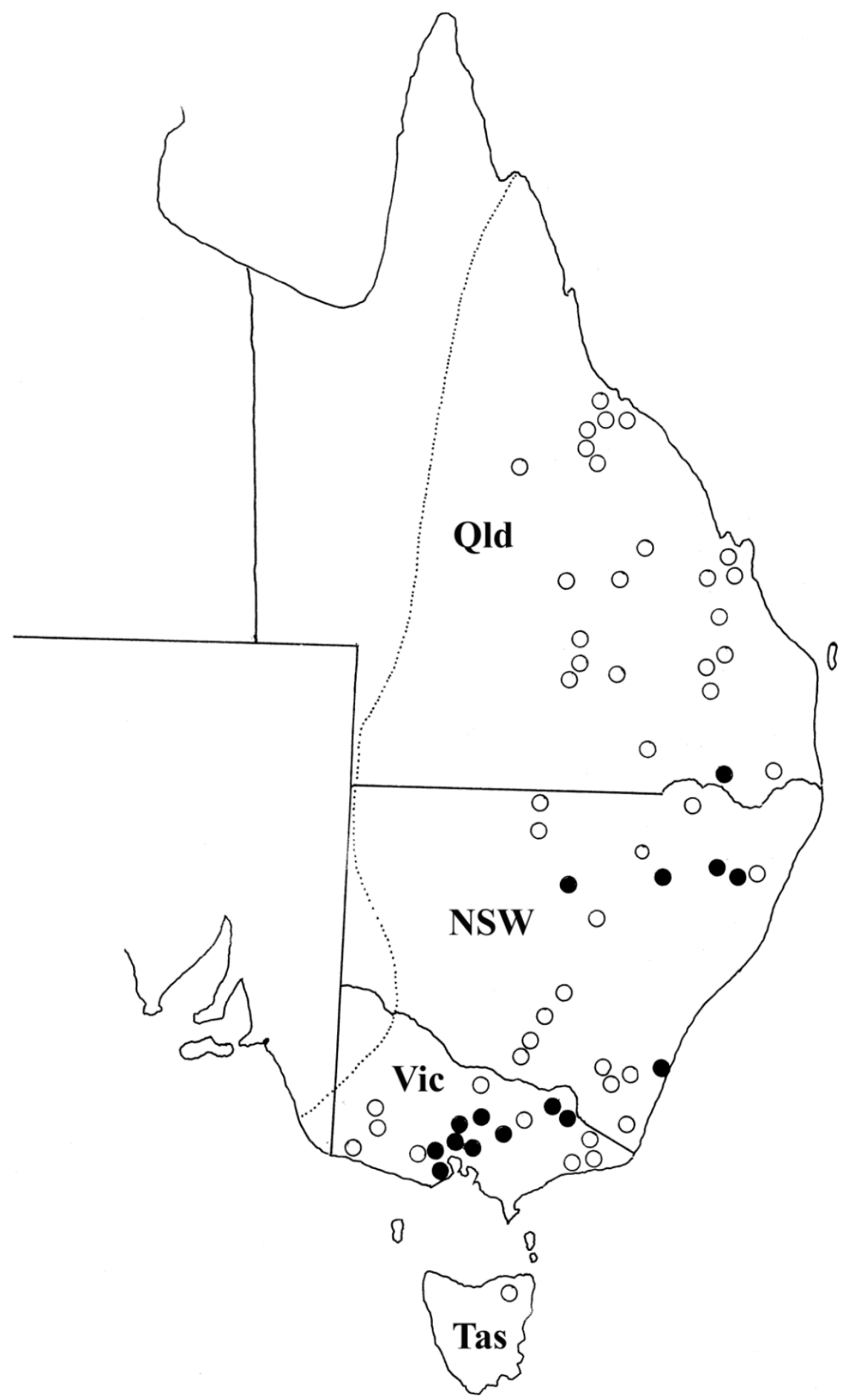

Figure 4. The geographic distribution of Torquenema toraliforme $\mathrm{n}$. comb. The dotted line represents the distribution of the host, Macropus giganteus based on Van Dyck and Strahan [9]. Open circles represent locations in which hosts have been examined but $T$. toraliforme was absent. Solid circles represent locations in which T. toraliforme was found. Abbreviations; Qld = Queensland, NSW = New South Wales, Vic = Victoria, Tas = Tasmania.

3.2. Description of a New Genus, Wallabicola $n . g$.

Order Strongylida (Molin, 1861)

Family Chabertiidae (Popova, 1952)

Subfamily Phascolostrongylinae Lichtenfels, 1980 
Wallabicola n. g.

Type species: Wallabicola dissimilis (Johnston and Mawson, 1939) n. comb.

\subsubsection{Generic Definition}

Robust nematodes. Anterior extremity deviated slightly ventrally; cephalic collar prominent, pierced by four sub-conical, sub-median papillae and two lateral amphids; mouth opening elongated laterally; four triangular sub-median teeth arise from anterior wall of buccal capsule; buccal capsule sub-cylindrical, heavily sclerotised; duct of dorsal oesophageal gland runs within wall of buccal capsule but at mid-length, divides internally forming Y-shaped dorsal gutter. Oesophagus clavate; nerve ring in anterior third of oesophagus; deirid papillate, at level of nerve ring; excretory at pore same level as deirid and nerve ring. Spicules elongate, alate. Vulva immediately anterior to anus; ovejector J-shaped. Parasitic in macropodid marsupials.

\subsubsection{Redescription of Wallabicola dissimilis n. comb.}

Wallabicola dissimilis (Johnston and Mawson, 1939) n. comb.

Synonyms: Cyclostrongylus dissimilis Johnston and Mawson, 1939;

Macropostrongyloides dissimilis (Johnston \& Mawson, 1939) Mawson, 1977.

Types: holotype, SAM 42827.

Type locality: Milson Island, New South Wales, Australia ( $\left.33^{\circ} 31^{\prime} \mathrm{S} 151^{\circ} 11^{\prime} \mathrm{E}\right)$.

Type host: Wallabia bicolor (Desmarest,) (Marsupialia: Macropodidae).

Additional material examined: Queensland: 19, Toowoomba (SAM 6852); New South Wales: 1ㅇ, Nowra (SAM 10959); 10", 1ㅇ, Nadgee State Forest (SAM 47679); Victoria: $10^{\circ}$, Mitta Mitta (SAM 12098); 50 $0^{x}$, 4우, Kamarooka (SAM 6772, 30521); 10 , 1ㅇ, Buangor (SAM

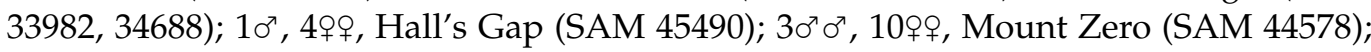

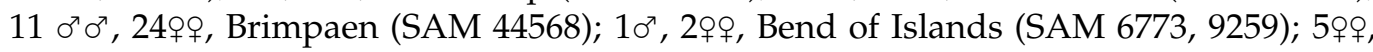
Healesville (SAM 32042); 1, Main Ridge (SAM 46300); 10', 2ㅇ, Portland (SAM 46289); $20^{7} \sigma^{7}, 2$ 우, Traralgon South (SAM 19458); $90^{7} 0^{7}$, 26우, Bonang (SAM 6774, 7261, 10569, 10596); 1요, Bemm River (SAM 6783).

Site in host: Stomach.

Representative DNA sequences: Ribosomal DNA first and second internal transcribed spacers sequences (Genbank Accession MK842126) from W. bicolor, Kamarooka, Victoria, Australia [5].

Etymology: The new generic name Wallabicola n. g. (masculine) is derived from 'incola' in Latin meaning inhabitant and Wallabia referring to the swamp wallaby, Wallabia bicolor, the host in which the new genus occurs.

\subsubsection{Redescription}

General (Figures 3c-f and 5a-1). Robust nematodes, red in colour when fresh. Body covered with numerous, fine transverse annulations, c. 0.001 apart. Anterior extremity deviated slightly ventrally; cephalic collar prominent, pierced by four sub-conical, submedial papillae and two lateral amphids; mouth opening elongated laterally; cephalic collar projects into mouth opening adjacent to amphids, with apical inflection, membrane surrounding teeth joined; four triangular sub-median teeth arise from anterior wall of buccal capsule, project into lumen; membrane between teeth and wall of buccal capsule continuous with internal projections from amphidial region of cephalic collar and bifid dorsal and ventral projections on anterior margin of buccal capsule; buccal capsule subcylindrical, heavily sclerotised, longer than wide; duct of dorsal oesophageal gland runs within wall of buccal capsule but at mid-length, divides internally to form Y-shaped dorsal gutter, with branches passing internally near anterior margin of buccal capsule, joining ventrally. Oesophagus clavate; nerve ring in anterior third of oesophagus at slight oesophageal constriction; deirid papillate, at level of nerve ring; excretory pore at about same level as deirid and nerve ring. 


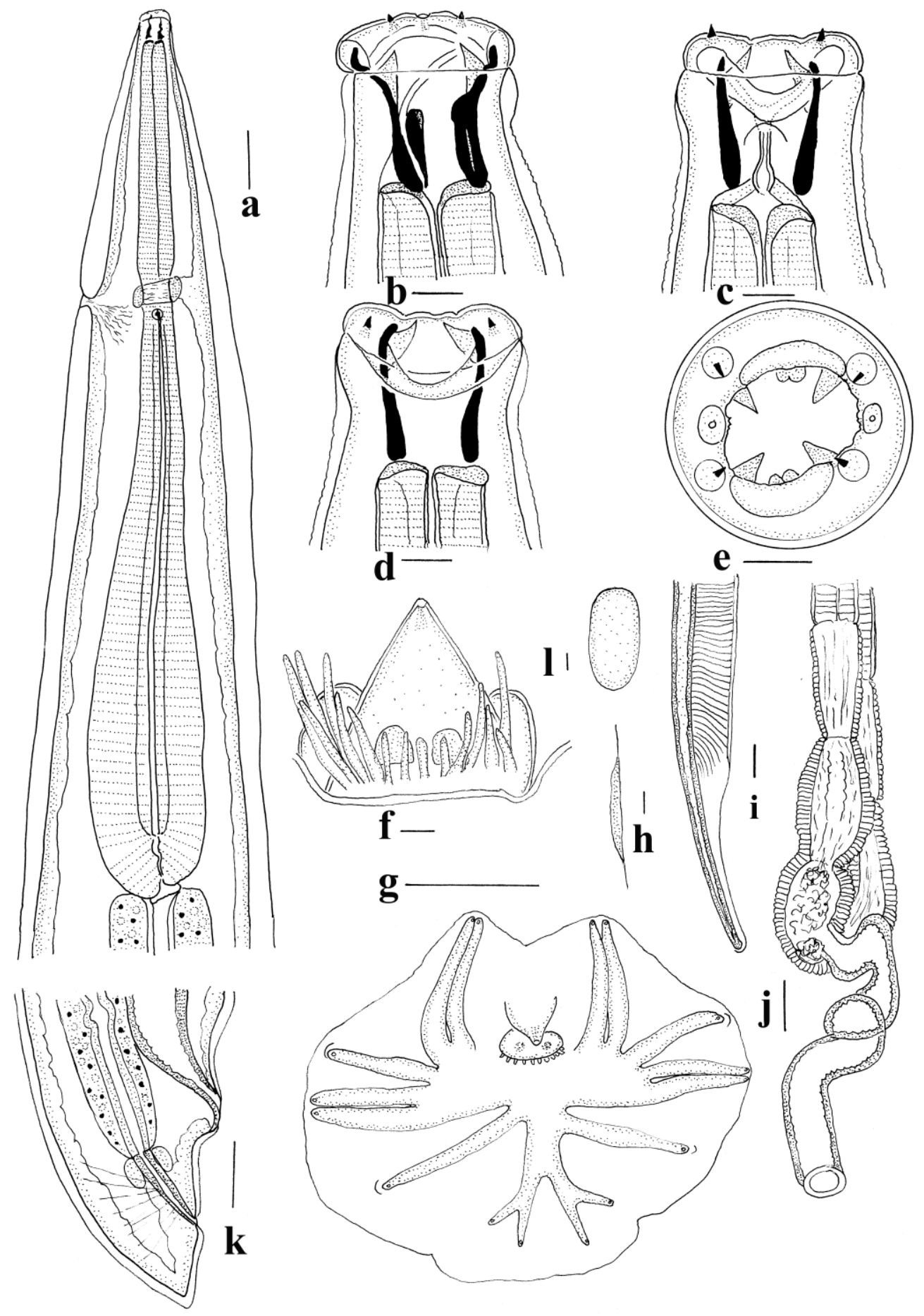

Figure 5. Wallabicola dissimilis n. comb. (a) Anterior region, lateral view; (b) Buccal capsule, lateral view; (c) Buccal capsule, dorsal view; (d) Buccal capsule, ventral view; (e) Buccal capsule, apical view; (f) Genital cone, dorsal view; (g) Bursa, apical view; (h) Gubernaculum, lateral view; (i) Spicule tip, lateral view; (j) Vagina and ovejector, lateral view; (k) Female tail, lateral view; (1) Gubernaculum, dorsal view. Scale-bars: (a,g,j), $0.1 \mathrm{~mm} ;(\mathbf{b}-\mathbf{f}, \mathbf{h}, \mathbf{i}, \mathbf{l}), 0.01 \mathrm{~mm}$.

Male (measurements of 10 specimens). Length 11-16 (13.6); maximum width 0.41-0.48 (0.45); buccal capsule 0.025-0.038 (0.029) deep, 0.018-0.023 (0.020) wide; oesophagus 0.89-1.10 (1.01) long; nerve ring, excretory pore and deirid 0.30-0.40 (0.35), 0.32-0.40 (0.36) and 0.34-0.41 (0.38) from anterior end respectively. Bursa short, stout; lateral and ventral lobes fused, ventral lobes joined ventrally; dorsal lobe shorter than ventro-lateral 
lobes, with slight median indentation. Ventro-ventral and ventro-lateral rays apposed, reaching margin of bursa; externo-lateral ray divergent from lateral trunk, not reaching margin of bursa, terminating in slight elevation on surface of bursa; medio-lateral and postero-lateral rays apposed, reaching margin of bursa; externo-lateral ray originating at base of dorsal trunk, not reaching margin of bursa, terminating in slight elevation on surface of bursa; dorsal ray slender at origin, dividing at mid-length; external branchlets directed postero-laterally, not reaching margin of bursa; internal branchlets directed posteriorly, not reaching margin of bursa; spicules 2.40-2.78 (2.53) long, alate; ala with numerous transverse striations; anterior extremity of spicules irregularly knobbed; distal extremity blunt; ala diminishes gradually towards distal tip of spicule, losing transverse striations; ventral lip of genital cone conical, bearing papilla 0; dorsal lip with paired appendages (papillae 7) closely applied to cloaca; dorsal to them array of elongate papillae; gubernaculum poorly sclerotised, ovoid and laterally elongated in dorso-ventral view 0.030-0.0.035 (0.032) long, slender in lateral views, not clearly visible in all specimens.

Female (measurements of 10 specimens). Length 16-24 (18.8); maximum width 0.49-0.56 (0.53); buccal capsule 0.020-0.030 (0.025) deep, 0.018-0.025 (0.020) wide; oesophagus $0.96-1.13$ (1.05) long; nerve ring, excretory pore and deirid 0.34-0.40 (0.36), 0.34-0.43 $(0.38)$ and $0.37-0.44$ (0.41) from anterior end respectively. Tail short conical, $0.12-0.15(0.13)$; vulva $0.29-0.39$ (0.36) from posterior end; vagina slightly convoluted $0.40-0.52(0.47)$ long; ovejector J-shaped; eggs thin-shelled, ellipsoidal 0.14-0.16 (0.15) long, 0.07-0.09 (0.08) wide.

\subsubsection{Remarks}

Wallabicola n. g. most closely resembles Macropostrongyloides, differing in the J-shaped ovejector and its occurrence within the stomach of its host. The new genus is differentiated from other phascolostrongyline genera (except for Hypodontus and Corollostrongylus) by its ventrally deviated head.

The current re-description of this species confirms most of the observations of Beveridge and Mawson [2] and Beveridge [1] while adding additional details of the spicule tip and cephalic structures. The description of the cephalic structures presented here differs significantly from that of Beveridge and Mawson [2], particularly in the position of the amphids. The cephalic extremity of $W$. dissimilis is extremely small and difficult to study under the light microscope. However, the scanning electron photomicrographs presented here provide novel information (Figure 3c-f). As with species of Macropostrongyloides, the buccal capsule contains four sub-median teeth with a flap-like structure resembling a leaf crown element arising between the tooth and the margin of the buccal capsule. Sukee et al. [10] speculated that these, along with the 'denticles' might constitute a leaf crown if they were continuous. The comparable structure in $W$. dissimilis is continuous although denticles are lacking. It differs however in that in $W$. dissimilis the structure includes bifid projections on the dorsal and ventral aspect of the margin of the buccal capsule, which are absent in species of Macropostrongyloides, and the lateral tridents seen in Macropostrongyloides are replaced by internal projections of the cephalic collar. The peri-oral structures of $W$. dissimilis are therefore quite distinct from those found in Macropostrongyloides baylisi, M. mawsonae, $M$. spearei and $M$. woodi, but the observations presented here support the suggestion of Sukee et al. [10] that an unusual form of leaf crown is present at the anterior margin of the buccal capsule in these species.

The female genital system of $W$. dissimilis was re-described by Beveridge (Figure 3A, [1]), but was not shown it in its entirety. The entire system is shown in Figure 5j. The vagina is slightly convoluted with the degree of convolution differing between specimens.

The new genus is predominantly distributed in Victoria and New South Wales (Figure 6). Although the distribution of W. bicolor is continuous along the eastern coast of Australia from Victoria to far north Queensland, $W$. dissimilis is has rarely been encountered in Queensland [2,11]. 


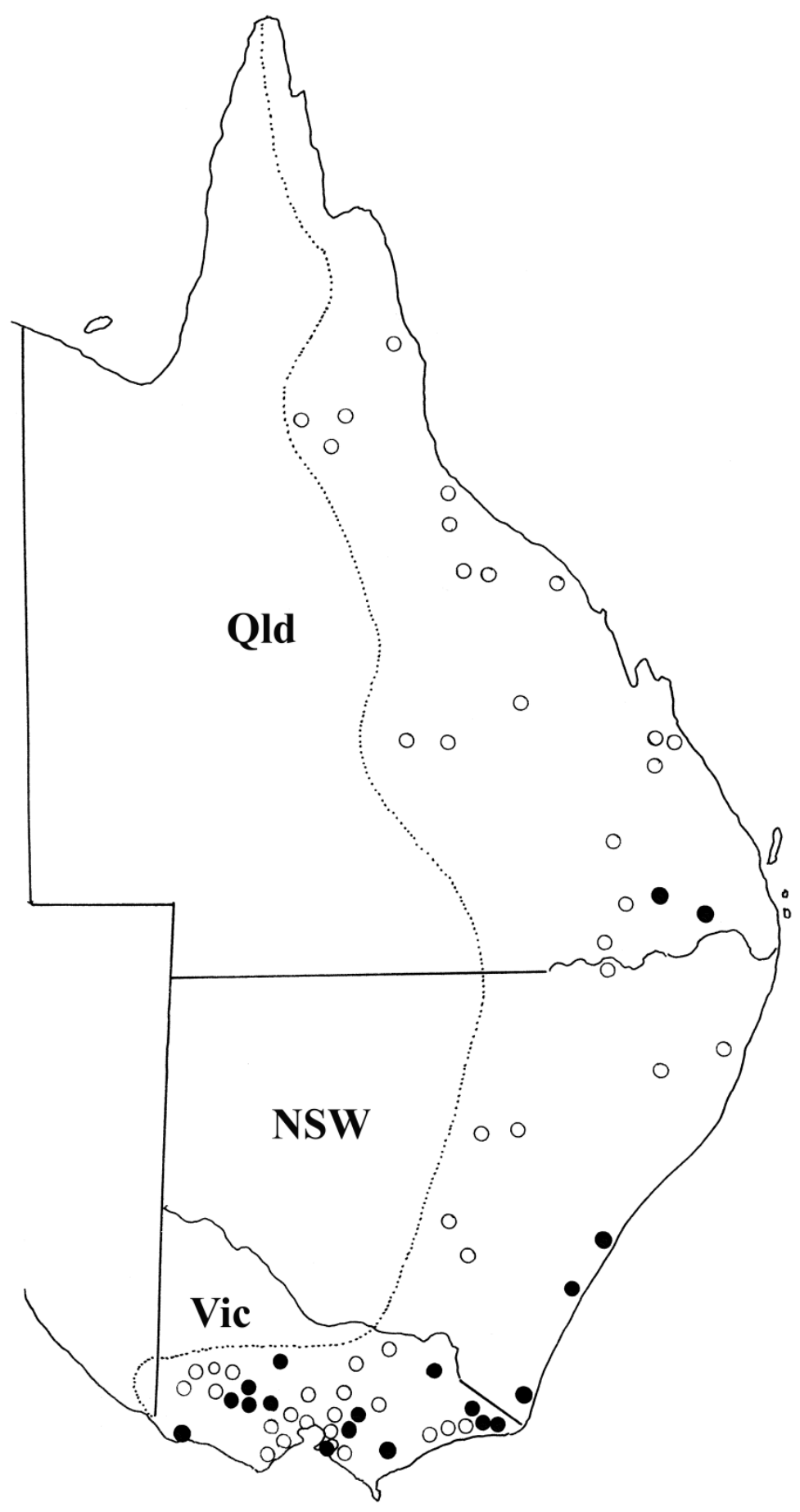

Figure 6. The geographic distribution of Wallabicola dissimilis $\mathrm{n}$. comb. The dotted line represents the distribution of the host, Wallabia bicolor based on Van Dyck and Strahan [9]. Open circles represent locations in which hosts have been examined but $W$. dissimilis was absent. Solid circles represent locations in which W. dissimilis were found. Abbreviations; Qld = Queensland, NSW = New South Wales, Vic $=$ Victoria.

3.3. Description of a New Species, Macropostrongyloides phascolomys n. sp.

Macropostrongyloides phascolomys n. sp.

Synonyms: Macropostrongylus lasiorhini Mawson, 1955; Macropostrongyloides lasiorhini (Mawson, 1955) Yamaguti, 1961 (in part).

Type specimens: holotype $\sigma^{7}$, (SAM 49056); allotype + , (SAM 59057); paratypes 307 $\sigma^{\top}, 1$, (SAM 30361). 
Type host: Vombatus ursinus (Shaw) (Marsupialia: Vombatidae).

Type locality: Bullengarook, Victoria, Australia $\left(37^{\circ} 31^{\prime} \mathrm{S} 144^{\circ} 29^{\prime} \mathrm{E}\right)$.

Additional material examined: from Vombatus ursinus: New South Wales: $50^{\top} 0^{7}, 20 \% 9$, Coolangubra State Forest (N 1511); $12 \sigma^{7} \sigma^{7}, 22 \circ 9$, composite collection from Bondo State Forest, Nimmo and Tharwa (N 1116); Victoria: $20^{7} 0^{7}, 4$ 우, Mount Pinnebar (SAM 13924).

\section{Site in host: Colon.}

Representative DNA sequence: Ribosomal DNA first and second internal transcribed spacers sequences (Genbank Accession MK842123) from V. ursinus, Bullengarook, Victoria, Australia [5].

Etymology: The new species is named after the former generic name of the host, Phascolomys.

\subsubsection{Description}

General (Figure 7a-k). Robust nematodes, pink in colour when fresh. Body without transverse annulations. Anterior extremity with prominent cephalic collar, pierced by four sub-conical, sub-medial papillae and two lateral amphids; mouth opening circular; four triangular sub-median teeth arise from anterior wall of buccal capsule, project into lumen; petaloid membrane present between teeth and wall of buccal capsule; bifid or trifid membranous structure present at anterior margin of buccal capsule, internal to each amphid; paired denticles present on anterior margin of buccal capsule dorsally and ventrally; buccal capsule sub-cylindrical, heavily sclerotised, longer than wide; duct of dorsal oesophageal gland runs within wall of buccal capsule but at mid-length, divides internally to form Y-shaped dorsal gutter, with branches passing internally near anterior margin of buccal capsule, joining ventrally. Oesophagus clavate; nerve ring in anterior third of oesophagus at slight oesophageal constriction; deirid papillate, at level of nerve ring; excretory pore at about same level as deirid and nerve ring.

Male (measurements of 10 specimens). Length 10-14 (11.7); maximum width 0.32-0.43 (0.38); buccal capsule 0.028-0.038 (0.033) deep, 0.025-0.030 (0.028) wide; oesophagus 0.710.82 (0.77) long; nerve ring, excretory pore and deirid 0.29-0.36 (0.32), 0.31-0.38 (0.35) and $0.35-0.45$ (0.39) from anterior end respectively. Bursa short, stout; lateral and ventral lobes fused, ventral lobes joined ventrally; dorsal lobe shorter than ventro-lateral lobes, without median indentation. Ventro-ventral and ventro-lateral rays apposed, reaching margin of bursa; externo-lateral ray divergent from lateral trunk, not reaching margin of bursa; medio-lateral and postero-lateral rays apposed, reaching margin of bursa; externo-lateral ray originating at base of dorsal trunk, not reaching margin of bursa; dorsal ray slender at origin, dividing almost at origin; external branchlets directed posteriorly, not reaching margin of bursa; internal branchlets shorter, directed posteriorly, not reaching margin of bursa; spicules 1.00-1.18 (1.11) long, alate; ala with numerous transverse striations; anterior extremity of spicules irregularly knobbed; distal extremity blunt; ala diminishes abruptly towards distal tip of spicule, losing transverse striations; ventral lip of genital cone conical, bearing papilla 0 ; ridge ventral to lip bears two lateral projections; dorsal lip with paired appendages (papillae 7) closely applied to cloaca; lateral to them single elongate papilla projects from base of cone; prominent conical projection present in mid-line of internal surface of dorsal lobe; gubernaculum prominent, elongate with posterior section broader in dorso-ventral view $0.025-0.045(0.035)$ long, slender in lateral views.

Female (measurements of 10 specimens). Length 14-18 (16.0); maximum width 0.45-0.69 (0.61); buccal capsule $0.030-0.040$ (0.035) deep, $0.025-0.030$ (0.028) wide; oesophagus 0.78 1.13 (1.02) long; nerve ring, excretory pore and deirid 0.31-0.40 (0.35), 0.29-0.43 (0.35) and $0.30-0.44$ (0.38) from anterior end respectively. Tail short conical, 0.09-0.13 (0.11); vulva $0.22-0.31$ (0.27) from posterior end; vagina straight, $0.38-0.48$ (0.42) long; ovejector Y-shaped; eggs thin-shelled, ellipsoidal 0.12-0.16 (0.14) long, 0.04-0.07 (0.06) wide. 

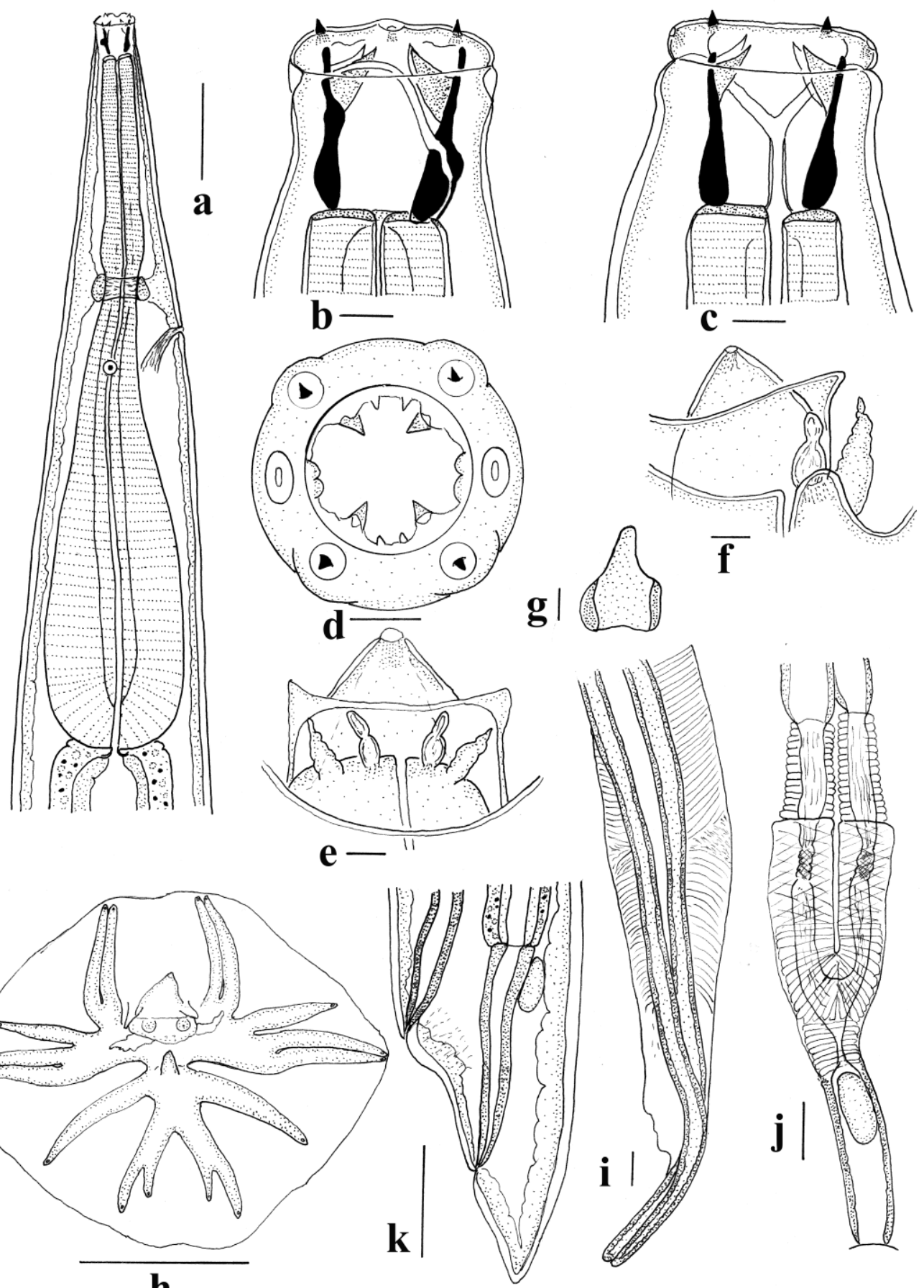

h

Figure 7. Macropostrongyloides phascolomys n. sp. (a) Anterior region, lateral view; (b) Buccal capsule, lateral view; (c) Buccal capsule, dorsal view; (d) Mouth, apical view; (e) Genital cone, dorsal view; (f) Genital cone, lateral view; (g) Gubernaculum, dorsal view; (h) Bursa, apical view; (i) Spicule tip, lateral view; (j) Vagina and ovejector, lateral view; (k) Female tail, lateral view. Scale-bars: (a,e-h,j-k), $0.1 \mathrm{~mm} ;(\mathbf{b}-\mathbf{d}, \mathbf{i}), 0.01 \mathrm{~mm}$.

\subsubsection{Remarks}

The new species is very similar to M. lasiorhini with which it has been confused in the past. The females of the two species are indistinguishable and the only character separating the males is the morphology of the genital cone which has a ridge ventral to the ventral lobe of the cone and a pair of lateral projections on the two sides of the base of the dorsal 
part of the cone. In M. lasiorhini, the dorsal lobe of the cone is surrounded by numerous projections, some of which are bifid terminally. The spicule tip of M. lasiorhini has not been described in detail previously but it is distinguishable from the spicule tip of $M$. phascolomys $\mathrm{n}$. sp. The comparisons between the spicule tips of M. lasiorhini and M. phascolomys n. sp. are shown in Figure 8a-c. There is a slight bend in the spicule tip of M. phascolomys n. sp. compared to the almost 45 degree bend in the spicule tip of $M$. lasiorhini (Figure 8b,c). The spicule ala in $M$. phascolomys terminates abruptly prior to reaching the end of spicule tip whereas in M. lasiorhini, the ala continues toward the end (Figure 8a) and wraps around the spicule tip in oblique views (Figure $8 b$ ). The striation patterns also differ between the two species, in M. lasiorhini the striation patterns change orientation further from the spicule tip and diminishes completely (Figure 8a,b) whereas in M. phascolomys n. sp., after the change in orientation the striations continue until almost reaching the end of the ala (Figure 8c).
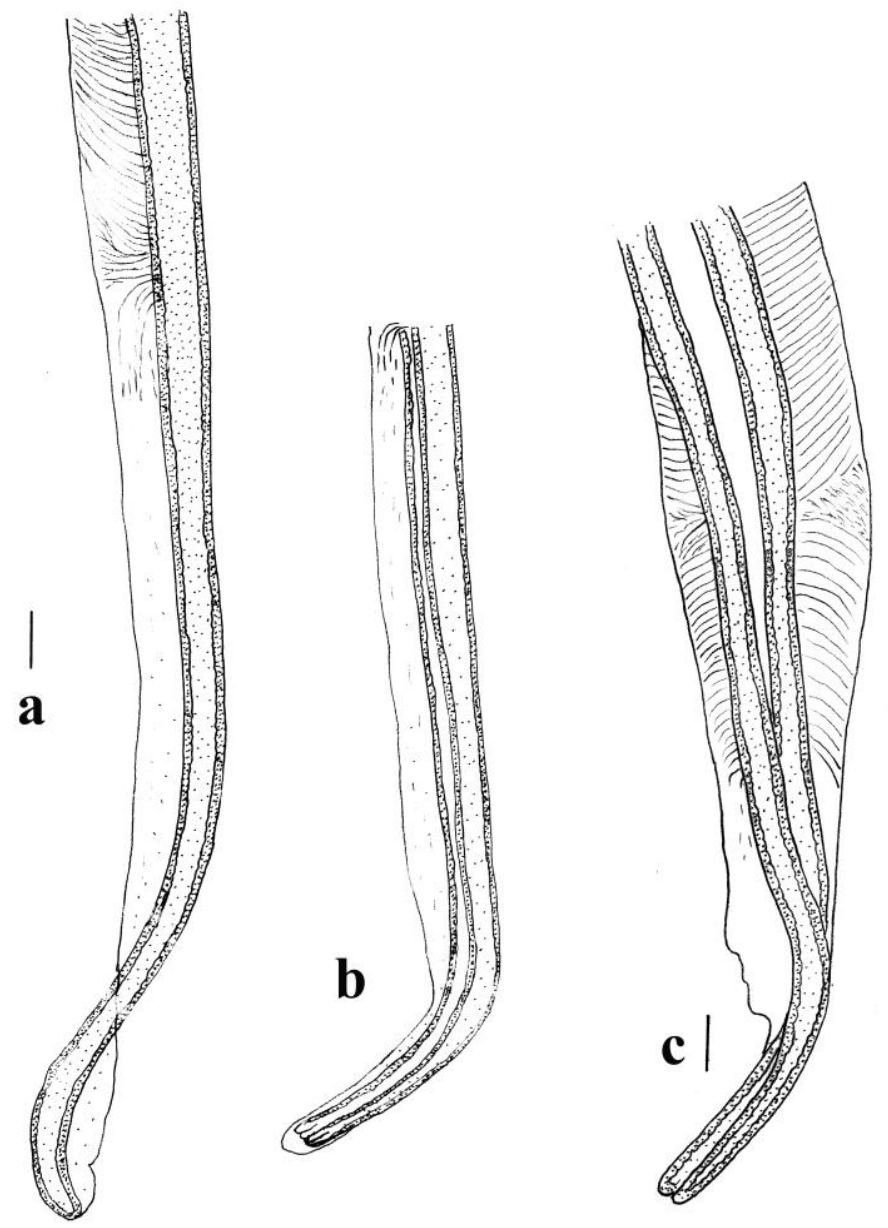

Figure 8. Comparative views of the spicule tips of Macropostrongyloides lasiorhini and Macropostrongyloides phascolomys n.sp. (a) Spicule tip of Macropostrongyloides lasiorhini, lateral view; (b) Spicule tip of Macropostrongyloides lasiorhini, oblique view; (c) Spicule tip of Macropostrongyloides phascolomys n. sp., lateral view. Scale-bars: $0.01 \mathrm{~mm}$.

The wombat host species of M. phascolomys n. sp. and M. lasiorhini also differ, with the former species occurring in V. ursinus and the latter in L. latifrons.

\section{Discussion}

Examination of specimens previously identified as $P$. toraliformis and M. dissimilis revealed differential morphological features which warrant the transfer of these species into two new genera, Torquenema n. g. and Wallabicola n. g., respectively. The study also 
found that M. lasiorhini from V. ursinus varied from specimens in the type-host, L. latifrons; therefore, permitting the description of a new species $M$. phascolomys $\mathrm{n}$. sp., which is restricted to $V$. ursinus. The new genera and species described here are supported by previous molecular data $[3,5]$.

Whilst the current descriptions of the genera Torquenema and Wallabincola are largely consistent with previous work by Beveridge and Mawson [2], additional informative characters have been added to the current descriptions. The structure of the deirids is relatively uniform throughout the species of the Phascolostrongylinae and is short and papillate in shape. In the Cloacininae, the deirid is elongate and hair-like, and this difference may provide a means of separating the two sub-families. The structure was overlooked in previous taxonomic descriptions. The use of scanning electron microscopy has enabled detailed observations of the peri-oral structures, including the flap-like projections associated with the teeth of $W$. dissimilis and denticles of $T$. toraliforme. A previous study of Macropostrongyloides spp. observed similar structures and speculated that the peri-oral projections may be leaf-crowns given that they extend the full length of the buccal capsule [10]. The SE photomicrographs of the mouth opening of T. toraliforme (Figure 3b) and $W$. dissimilis (Figure 3c,e,f) show that these peri-oral structures in both species appeared to be continuous around the buccal capsule rather than projecting as individual elements, suggesting that the structures could potentially be considered leaf-crowns. The presence of leaf-crown elements is characteristic of some genera of the subfamily Cloacininae and has only been observed in the subfamily Phascolostrongylinae in the genera Phascolostrongylus and Oesophagostomoides from wombats [1]. Whether this is also the case in other genera and species within the Phascolostrongylinae is not known and additional SEM examination is required, particularly of Paramacropostrongylus, Macropostrongyloides yamagutii and $M$. lasiorhini which possess both teeth and denticles.

The shapes of the ovejector were used to differentiate the genera Torquenema n. g. and Wallabincola $\mathrm{n}$. g. from their former genera. The presence of a Y-shape muscular ovejector is considered a plesiomorphic character within the Strongyloidea [12,13]. The genus Torquenema n. g. is differentiated from the genus Paramacropostrongylus by the presence of a Y-shaped ovejector and the genus Wallabincola is distinguished from Macropostrongyloides based on its J-shaped ovejector. In this study, the shape of the ovejector has been used as a generic character. However, the shape of the ovejector is not always reliable as a generic character. In the genus Cloacina for instance, species possess either a Y-shaped or J-shaped ovejector [14].

The geographic distribution of $T$. toraliforme and $W$. dissimilis appears to be primarily in the southern region of the distributions of their hosts (Figures 4 and 6). Similar patterns have been observed in Macropostrongyloides mawsonae from M. giganteus which is predominantly encountered in the southern region of Australia but rarely detected in the northern part of Australia despite the continuous distribution of the host [10]. Previous molecular studies $[3,5]$ have indicated genetic differences between specimens of $W$. dissimilis from Queensland and those collected from Victoria. No morphological differences were detected between these two genotypes in the current study, but the existence of a cryptic species cannot be eliminated. Torquenema n. g. occurs primarily in M. giganteus in Victoria whereas Paramacropostrongylus iugalis occurs in the same host in northern New South Wales and central Queensland [15].

Macropostrongyloides phascolomys n. sp. occurs in V. ursinus while M. lasiorhini, occurs in L. latifrons. Fossil records show that the wombat genus Lasiorhinus once had a wider distribution and was present in Victoria, New South Wales in Queensland between the late-Miocene to mid-Pliocene period [16]. This suggests that in the past, Lasiorhinus and Vombatus may have been sympatric while the current geographic distribution of M. lasiorhini and $V$. ursinus is allopatric. Therefore, the two species of Macropostrongyloides may have undergone co-speciation with their respective hosts. 


\section{Conclusions}

The present study described two new genera and a new species from the subfamily Phascolostrongylinae supporting previous molecular evidence $[3,5,17]$. Future studies utilising the nuclear and mitochondrial DNA sequence data could provide better insights into the evolution of this highly diverse group of parasitic nematodes from herbivorous Australian marsupials.

Author Contributions: Conceptualisation, I.B. and T.S.; methodology, I.B. and T.S.; formal analysis, I.B. and T.S.; data curation, I.B. and T.S.; writing — original draft preparation, I.B. and T.S.; writingreview and editing, I.B., T.S., and A.J.; visualisation I.B. and T.S.; supervision, I.B. and A.J.; funding acquisition, I.B., T.S. and A.J. All authors have read and agreed to the published version of the manuscript.

Funding: This study was financially supported by the Australian Biological Resources Study grants RF217-06 and CBG18-07.

Institutional Review Board Statement: Not applicable.

Informed Consent Statement: Not applicable.

Data Availability Statement: This article was registered under the Official Register of Zoological Nomenclature (ZooBank) as urn:lsid:zoobank.org:pub:F9E8C1F1-2C75-4B75-BF70-7888599B5C7B. The new genera Torquenema and Wallabicola were registered as urn:lsid:zoobank.org:act:0CF562C1-BF534C9B-99C4-03D35FEC99A4 and urn:lsid:zoobank.org:act:06678CBD-5F42-4424-93D8-8CF09C664F91, respectively. The new species Macropostrongyloides phascolomys was registered as urn:lsid:zoobank.org: act:2FB8A60F-8748-4D42-A7C8-BE1327FC6051.

Acknowledgments: We would like to acknowledge Allison van de Meene from the Biosciences Microscopy unit, Melbourne University for her advice and assistance with the scanning electron microscopy. We would also like to thank David Spratt from CSIRO for providing specimens.

Conflicts of Interest: The authors declare no conflict of interest.

\section{References}

1. Beveridge, I. The systematic status of Australian Strongyloidea (Nematoda). Bull. Mus. Natl. Hist. Nat. 1987, 9, 109-126.

2. Beveridge, I.; Mawson, P.M. A taxonomic revision of the genera Macropostrongyloides Yamaguti and Paramacropostrongylus Johnston \& Mawson (Nematoda: Trichonematidae) from Australian marsupials. Aust. J. Zool. 1978, 26, 763-787.

3. Sukee, T.; Beveridge, I.; Sabir, A.J.; Jabbar, A. Phylogenetic relationships within the nematode subfamily Phascolostrongylinae (Nematoda: Strongyloidea) from Australian macropodid and vombatid marsupials. Microorganisms 2021, 9, 9. [CrossRef]

4. Mawson, P.M. Revision of the genus Macropostrongylus and descriptions of three new genera: Popovastrongylus, Dorcopsinema and Arundelia (Nematoda: Trichonematidae). Trans. R. Soc. S. Aust. 1997, 101, 51-62.

5. Sukee, T.; Beveridge, I.; Chilton, N.B.; Jabbar, A. Genetic variation within the genus Macropostrongyloides (Nematoda: Strongyloidea) from Australian macropodid and vombatid marsupials. Parasitology 2019, 146, 1673-1682. [CrossRef] [PubMed]

6. Chabaud, A.G.; Puylaert, F.; Bain, O.; Petter, A.J.; Durette-Desset, M.C. Remarques sur 1' homologie entre les papilles cloacales des Rhabditides et les côtes dorsales des Strongylida. C. R. Hebd. Séances Acad. Sci. 1970, 271, 1771-1774. (In French)

7. Jackson, S.; Groves, C. Taxonomy of Australian mammals; CSIRO Publishing: Clayton South, Australia, 2015; p. 529.

8. Beveridge, I. New species of parasitic nematodes of the genus Cloacina (Nematoda: Strongyloidea) from the banded hare wallaby, Lagostrophus fasciatus (Marsupialia: Macropodidae). Trans. R. Soc. S. Aust. 2014, 138, 249-256. [CrossRef]

9. Van Dyck, S.; Strahan, R. The Mammals of Australia, 3rd ed.; New Holland Publishers: Chatswood, UK, 2008; p. 756.

10. Sukee, T.; Beveridge, I.; Jabbar, A. New species of Macropostrongyloides Yamaguti, 1961 (Nematoda: Strongylida) and the redescription of Ma. baylisi (Wood, 1930) from Australian macropodid marsupials. Syst. Parasitol. 2020, 97, 267-284. [CrossRef]

11. Beveridge, I. The gastro-intestinal helminth parasites of the swamp wallaby, Wallabia bicolor (Desmarest) (Marsupialia: Macropodidae), and their regional distribution. Trans. R. Soc. S. Aust. 2016, 140, 203-227. [CrossRef]

12. Lichtenfels, J.R. A conventional approach to a new classification of the Strongyloidea, nematode parasites of mammals. Am. Zool. 1979, 19, 1185-1194. [CrossRef]

13. Lichtenfels, J.R. Keys to genera of the superfamily Strongyloidea No. 7. In CIH Keys to the Nematode Parasites of Vertebrates; Anderson, R.C., Chabaud, A.G., Willmott, S., Eds.; Commonwealth Agricultural Bureaux: Farnham Royal, UK, 1980; p. 41.

14. Beveridge, I. Taxonomic revision of the genus Cloacina von Linstow (Nematoda: Strongyloidea) from macropodid marsupials. Invertebr. Syst. 1998, 12, 273-508. [CrossRef] 
15. Chilton, N.B.; Beveridge, I.; Andrews, R. Electrophoretic and morphological analysis of Paramacropostrongylus typicus (Nematoda: Strongyloidea), with the description of a new species, Paramacropostrongylus iugalis, from the eastern grey kangaroo Macropus giganteus. Syst. Parasitol. 1993, 24, 35-44. [CrossRef]

16. Murray, P.F. Palaeontology and palaeobiology of wombats. In Wombats; Wells, R.T., Pridmore, P.A., Eds.; Surrey Beatty \& Sons: Chipping Norton, Australia, 1998; pp. 1-33.

17. Sukee, T.; Koehler, A.V.; Hall, R.; Beveridge, I.; Gasser, R.B.; Jabbar, A. Phylogenetic analysis of mitogenomic data sets resolves the relationship of seven Macropostrongyloides species from Australian macropodid and vombatid marsupials. Pathogens 2020, $9,1042$. [CrossRef] 